\title{
Casein kinase 1: a new tale of chronic lymphocytic leukemia (CLL) microenvironment
}

\author{
Stefania Fiorcari, Rossana Maffei, Roberto Marasca \\ Hematology Unit, Department of Medical and Surgical Sciences, University of Modena and Reggio Emilia, Modena, Italy \\ Correspondence to: Prof. Roberto Marasca, MD. Hematology Unit, Department of Medical and Surgical Sciences, University of Modena and Reggio \\ Emilia, Via Del Pozzo 71, Modena 41124, Italy. Email: roberto.marasca@unimore.it. \\ Comment on: Janovska P, Verner J, Kohoutek J, et al. Casein kinase 1 is a therapeutic target in chronic lymphocytic leukemia. Blood 2018;131:1206-18.
}

Submitted May 20, 2018. Accepted for publication Jun 11, 2018.

doi: $10.21037 /$ tcr.2018.06.21

View this article at: http://dx.doi.org/10.21037/tcr.2018.06.21

The biological history of chronic lymphocytic leukemia (CLL) is strictly related to the ability of leukemic cells to invade and manipulate tissue microenvironments. This evidence is unequivocal by the observation that despite an apparent long life in vivo, CLL cells undergo in spontaneous apoptosis in vitro during culture in complete medium (1). This can be avoided by culturing CLL cells in presence of a feeder layer represented by stromal cells (2), endothelial cells (3) and macrophage population (also called nurse-like cells) (4). In this perspective, CLL cells recirculate from blood to tissues through transient interactions with endothelium through firm adhesion molecules and chemokines that trigger integrin activation, thus inducing firm adhesion and transendothelial migration into tissues where stromal cells guide lymphocyte homing retention (5). CLL cells infiltrate bone marrow and lymph node compartments, disrupting the physiological architecture of tissues and generating hallmark structures called proliferation centers (6). Inside tissue microenvironments, CLL cells establish a complex crosstalk with surrounding non-transformed cells of stromal and immune compartments manipulating its biological functions. This crosstalk protects CLL cells from spontaneous or drug-induced apoptosis contributing to genetic instability and establishing a protective niche hiding residual CLL cells from conventional drugs (7). In the last years, novel kinase inhibitors of B-cell receptor signaling pathway (BCRi) have been approved for the treatment of CLL patients. These drugs, as ibrutinib and idelalisib, cause rapid resolution of lymphadenopathy and/or organomegaly with redistribution of leukemic cells from tissues into the blood (8).

This peculiar activity suggests that these agents interfere with CLL cell adhesion and other tissue retention signals
(9-11). Despite the important benefits of these agents, it's now clear the subsistence of multiple side effects (12). and the existence of intrinsic and extrinsic resistance (13-15). All these observations remark that CLL is still an incurable disease and the new treatments are not still curative, opening the possibility to associate in the clinical practice different therapeutic strategies.

In this study published on Blood, Janovska and colleagues (16) introduced a new player in the complex crosstalk between CLL cells and microenvironment. Casein kinase $1 \delta / \varepsilon$ is a key component in the $\mathrm{Wnt} /$ polarity proteins pathway (PCP). Non-canonical Wnt/PCP pathway is significant for communication of CLL cells with accessory cells in tissue microenvironments regulating chemotaxis and transendothelial migration in the chemokine gradient and in vivo homing of CLL cells. PCP pathway contributes to CLL pathogenesis mainly via regulation of chemotactic responses to chemokines. Of interest, PCP-high patients group showed worse clinical parameters as treatmentfree survival promoting the idea that PCP pathway may contribute to the CLL pathogenesis (17).

Of note, CK1 was overexpressed in CLL cells compared with B cells isolated donors. This data make CK1 a suitable specific therapeutic target in CLL cells. To dissect the role of CK1 in the process of homing and retention of CLL cells inside tissue niches, the authors used specific adenosyl triphosphate-competing CK1 inhibitors. One of this, PF670462 inhibited both CK1 $\delta$ and CK1 $1 \varepsilon$ isoforms. First, CK1 $\delta / \varepsilon$ isoforms were involved in CLL cells migration towards CCL19 and CXCL12 chemokines, bone marrow stromal cells and in integrin-mediated adhesion. Inhibition of both isoforms of CK1 by PF-670462 was able to 
counteract CLL cells chemotaxis, suggesting the possibility to interfere with CLL cell trafficking using this compound. Moreover, inhibition of CK $1 \delta / \varepsilon$ isoforms determined a significant reduction of CCL 3 and CCL4, that are secreted by CLL cells and recruit accessory cells that in turn can deliver pro-survival signals. These results opened the possibility to combine the inhibition of CK1 with the inhibition of BTK, key player in CLL pathogenesis. Since ibrutinib is able to interfere with CLL chemotaxis, the authors combined PF-670462 with BTK inhibition founding a significant reduction of CLL cells migration towards CCL19 and CXCL12. Lastly, the authors analyzed the synergistic combination of PF-670462 and ibrutinib in a mouse model. The combination showed to be most effective compared with single treatment and it was able to stopped accumulation of leukemic cells in peripheral blood and spleen. In addition, CK1 inhibition slowed down the progression in mice after ibrutinib cessation.

The study of Janovska et al. provides new insights in the complexity of CLL cells interaction with microenvironmental accessory cells illustrating the role of a new player. Given the increasing knowledge about the importance of microenvironment in the maintenance of leukemic cells, the possibility to find new appealing target in CLL adds new alternative to the therapeutic targets strategies based on BCR and antiapoptotic signaling inhibition. Moreover, it opens new queries about the possibility to use for example ibrutinib with other pharmacological agents. A key question become if CK1 inhibitors could overcome the resistance to BCRi and how these CK1 inhibitors alone or in combination with BCRi could be used in the clinical practice. From a therapeutic view, a new PI3K delta inhibitor, umbralisib (TGR-1202) possesses also the unique capability to inhibit $\mathrm{CK} 1 \varepsilon$, which distinguishes it from idelalisib. CK1 $\varepsilon$ is able to activate mRNA translation through phosphorylation of 4E-BP1 orchestrating upstream signals as c-Myc. Umbralisib disrupts the 4E-BP1-c-Myc axis inducing death in lymphoma cells, it is currently in phase 3 clinical trial showing promising good activity and, of importance, differs from the other $\mathrm{PI} 3 \mathrm{~K} \delta$ inhibitors by a better safety profile (18).

In conclusion, this manuscript inserts a new piece in the complex puzzle of CLL microenvironment: CK1 may play a relevant role as a new therapeutic target in CLL.

\section{Acknowledgments}

Funding: This work was supported by Associazione Italiana per la Ricerca sul Cancro and Fondazione Cariplo
(TRIDEO 16923-R Maffei), AIRC IG14376 and PRIN 2015 ZMRFEA_002-R Maffei. S Fiorcari was supported by FIRC/AIRC Triennal Fellowship 16430, Milan, Italy and Fondazione Umberto Veronesi, Milan, Italy; Ricerca Finalizzata Giovani Ricercatori 2011-2012, Ministero della Salute (GR-2011-02349282-R Maffei), Rome, Italy. The funders had no role in study design, data collection and analysis, decision to publish or preparation of the manuscript.

\section{Footnote}

Provenance and Peer Review: This article was commissioned and reviewed by the Section Editor Peipei Xu (Department of Hematology, The Affiliated Drum Tower Hospital of Nanjing University Medical School, Nanjing, China).

Conflicts of Interest: All authors have completed the ICMJE uniform disclosure form (available at http://dx.doi. org/10.21037/tcr.2018.06.21). The authors have no conflicts of interest to declare.

Ethical Statement: The authors are accountable for all aspects of the work in ensuring that questions related to the accuracy or integrity of any part of the work are appropriately investigated and resolved.

Open Access Statement: This is an Open Access article distributed in accordance with the Creative Commons Attribution-NonCommercial-NoDerivs 4.0 International License (CC BY-NC-ND 4.0), which permits the noncommercial replication and distribution of the article with the strict proviso that no changes or edits are made and the original work is properly cited (including links to both the formal publication through the relevant DOI and the license). See: https://creativecommons.org/licenses/by-nc-nd/4.0/.

\section{References}

1. Collins RJ, Verschuer LA, Harmon BV, et al. Spontaneous programmed death (apoptosis) of B-chronic lymphocytic leukaemia cells following their culture in vitro. $\mathrm{Br} \mathrm{J}$ Haematol 1989;71:343-50.

2. Kurtova AV, Balakrishnan K, Chen R, et al. Diverse marrow stromal cells protect CLL cells from spontaneous and drug-induced apoptosis: development of a reliable and reproducible system to assess stromal cell adhesionmediated drug resistance. Blood 2009;114:4441-50. 
3. Maffei R, Fiorcari S, Bulgarelli J, et al. Physical contact with endothelial cells through beta1- and beta2- integrins rescues chronic lymphocytic leukemia cells from spontaneous and drug-induced apoptosis and induces a peculiar gene expression profile in leukemic cells. Haematologica 2012;97:952-60.

4. Tsukada N, Burger JA, Zvaifler NJ, et al. Distinctive features of "nurselike" cells that differentiate in the context of chronic lymphocytic leukemia. Blood 2002;99:1030-7.

5. Springer TA. Traffic signals for lymphocyte recirculation and leukocyte emigration: the multistep paradigm. Cell 1994;76:301-14.

6. Schmid C, Isaacson PG. Proliferation centres in B-cell malignant lymphoma, lymphocytic (B-CLL): an immunophenotypic study. Histopathology 1994;24:445-51.

7. Burger JA. Nurture versus nature: the microenvironment in chronic lymphocytic leukemia. Hematology Am Soc Hematol Educ Program 2011;2011:96-103.

8. Burger JA, Montserrat E. Coming full circle: 70 years of chronic lymphocytic leukemia cell redistribution, from glucocorticoids to inhibitors of B-cell receptor signaling. Blood 2013;121:1501-9.

9. Ponader S, Chen SS, Buggy JJ, et al. The Bruton tyrosine kinase inhibitor PCI-32765 thwarts chronic lymphocytic leukemia cell survival and tissue homing in vitro and in vivo. Blood 2012;119:1182-9.

10. Hoellenriegel J, Meadows SA, Sivina M, et al. The phosphoinositide 3'-kinase delta inhibitor, CAL-101, inhibits B-cell receptor signaling and chemokine networks in chronic lymphocytic leukemia. Blood 2011;118:3603-12. 11. Fiorcari S, Brown WS, McIntyre BW, et al. The PI3- kinase delta inhibitor idelalisib (GS-1101) targets integrinmediated adhesion of chronic lymphocytic leukemia (CLL) cell to endothelial and marrow stromal cells. PLoS One 2013;8:e83830.

12. de Weerdt I, Koopmans SM, Kater AP, et al. Incidence and management of toxicity associated with ibrutinib and idelalisib: a practical approach. Haematologica 2017;102:1629-39.

13. Lampson BL, Brown JR. Are BTK and PLCG2 mutations necessary and sufficient for ibrutinib resistance in chronic lymphocytic leukemia? Expert Rev Hematol 2018;11:185-94.

14. Maffei R, Fiorcari S, Martinelli S, et al. Targeting neoplastic B cells and harnessing microenvironment: the "double face" of ibrutinib and idelalisib. J Hematol Oncol 2015;8:60.

15. Fiorcari S, Maffei R, Audrito V, et al. Ibrutinib modifies the function of monocyte/macrophage population in chronic lymphocytic leukemia. Oncotarget 2016;7:65968-81.

16. Janovska P, Verner J, Kohoutek J, et al. Casein kinase 1 is a therapeutic target in chronic lymphocytic leukemia. Blood 2018;131:1206-18.

17. Kaucka M, Plevova K, Pavlova S, et al. The planar cell polarity pathway drives pathogenesis of chronic lymphocytic leukemia by the regulation of B-lymphocyte migration. Cancer Res 2013;73:1491-501.

18. Deng C, Lipstein MR, Scotto L, et al. Silencing c-Myc translation as a therapeutic strategy through targeting PI3Kdelta and CK1 epsilon in hematological malignancies. Blood 2017;129:88-99.
Cite this article as: Fiorcari S, Maffei R, Marasca R. Casein kinase 1: a new tale of chronic lymphocytic leukemia (CLL) microenvironment. Transl Cancer Res 2018;7(Suppl 7):S730S732. doi: 10.21037/tcr.2018.06.21 